\title{
Development and characterization of hyaluronic acid-lysine nanoparticles with potential as innovative dermal filling
}

\author{
Jaqueline Carneiro ${ }^{1 *}$, Patrícia Mathias Döll-Boscardin¹, Bárbara Celânia Fiorin², Jessica Mendes \\ Nadal $^{1}$, Paulo Vitor Farago ${ }^{1}$, Josiane Padilha de Paula ${ }^{1}$
}

\begin{abstract}
${ }^{1}$ Pharmaceutical Science Department, State University of Ponta Grossa, Ponta Grossa, PR, Brazil, ${ }^{2}$ Chemistry Department, State University of Ponta Grossa, Ponta Grossa, PR, Brazil
\end{abstract}

\begin{abstract}
Skin aging causes changes such as wrinkles and flaccidity leading to a large demand for aesthetic procedures, including dermal filling. A key agent in dermal filling is hyaluronic acid (HA), which is a naturally occurring glycosaminoglycan. However, it is a hydrophilic macromolecule that experiences great difficulty in crossing the skin barrier causing most commercial formulations containing it to be injectable, which in turn brings risks since they involve an invasive technique. In that sense, the aim of this study was to develop and characterize nanoparticles obtained from ionic interaction between HA and lysine (Lys) for use as a potential agent of dermal filling for topical application, increasing and improving its applicability and safety. To this end, nanoparticles were obtained by dripping of Lys over HA under magnetic stirring. A nanometric size was confirmed and a suitable surface charge was obtained by zeta potential. Nanoparticles were almost spherical in shape with a smooth surface. Interaction between raw materials for preparing nanoparticles was studied by FTIR and NMR spectroscopy and an ionic interaction was confirmed. These physicochemical features suggest that obtained nanoparticles can be further used as a topical dermal filling.
\end{abstract}

Uniterms: Nanotechnology. Skin aging/non-invasive method. Skin aging/treatment/study.

\section{INTRODUCTION}

Skin aging is a sign of progressive loss of skin tissue which can be attributed to factors such as epidermal or dermal cell loss and decrease of extracellular matrix, particularly glycosaminoglycans (GAG) (Robert, LabatRobert, Robert, 2012).

Different types of filler agents are used as cosmetic strategy in order to prevent or reverse loss of extracellular matrix (Sánchez-Carpintero, Candelas, Ruiz-Rodrígues, 2010). The most common fillers reported in literature and clinically used are as follows: collagen (bovine, porcine or human), synthetic or animal hyaluronic acid (HA), poly(L-lactic acid), calcium hydroxyapatite, poly(methyl methacrylate), silicon, and hydroxyethyl methacrylate (Sánchez-Carpintero, Candelas, Ruiz-Rodrígues, 2010). In that context, HA has become more popular and widely used as soft tissue filler due to its major advantages

\footnotetext{
*Correspondence: J. Carneiro. Departamentos de Ciências Farmacêuticas; Universidade Estadual de Ponta Grossa. Av. Carlos Cavalcanti, 4748 - 84030-900 - Ponta Grossa - PR, Brazil. E-mail: jaquelinec89@gmail.com
}

(Edwards, Fantasia, Iovino, 2006; Requena et al., 2011).

Hyaluronic acid is a GAG, a naturally occurring biopolymer, composed of alternating links between residues of D-glucuronic acid and $\mathrm{N}$-acetylglucosamine (Nelson, Cox, 2011). Considering its high hydrophilicity, HA can provide an improved moisture to skin and an enhanced viscoelasticity to dermal matrix (Brandt, Cassaniga, 2007; Born, 2006). In addition, HA is used as a transitory bioresorbable filler for treating wrinkles and expression lines and for increasing lip volume (Edwards, Fantasia, Iovino, 2006; Requena et al., 2011). However, formulations containing HA are injectable due to its high molar mass and can bring discomfort to patients (Beer, 2009). In that sense, nanostructured systems can be used in order to improve percutaneous absorption of HA and to avoid pain and discomfort that occur during invasive procedure.

Polymeric nanoparticles are widely reported as nanocarriers that can be successfully used to change physicochemical properties of an active agent leading to the improvement of its release into and/or its effect on skin (Guterres, Alvez, Pohlmann, 2007). For this purpose, 
lysine (Lys) was chosen for preparing nanoparticles by ionic complexation with HA since, being a natural polypeptide, both stability and biocompatibility would be ensured. A previous study reported the successful interaction between polypeptides and amino acids (Oyarzun-Ampuero et al., 2011).

Taking into account all these data, the aim of this study was to develop innovative polymeric nanoparticles of HA-Lys, obtained from ionic interaction, for use as a safe dermal filling, and characterize physicochemically ensuring its stability. Our hypothesis was that it is possible to obtain a stable material based on nanotechnology that can be further used as a non-invasive strategy for topical application of HA in order to avoid pain and discomfort to patients.

\section{MATERIAL AND METHODS}

\section{Material}

Hyaluronic acid Streptococcus equi $(10,000$ $30,000 \mathrm{~g} \mathrm{~mol}^{-1}$ ) was purchased from Sigma Aldrich (USA). L-Lysine hydrochloride (146.18 g. $\left.\mathrm{mol}^{-1}\right)$ was obtained from Fagron (Brazil). The other reagents and solvents were of analytical grade.

\section{Preparation of HA-Lys nanoparticles}

Hyaluronic acid-Lys (HA-Lys) complex was prepared as reported by Oyarzun-Ampuero et al. (2011), with some changes. Nanopaticles were obtained using $1 \mathrm{~mol}$ of HA and 16,400 mol of Lys in order to provide a molar equivalency. A Lys solution $\left(4.0 \times 10^{-2} \mathrm{~g} . \mathrm{mL}^{-1}\right)$ was dropped into a HA solution (3.5 $\times 10^{-4}$ g.mL $\mathrm{mL}^{-1}$ ) using a burette (inner diameter of 1 $\mathrm{cm})$ under magnetic stirring $(1,700 \mathrm{rpm})$ at a drip rate of $2.5 \mathrm{~mL} . \mathrm{min}^{-1}$. Final colloidal suspension was then dried at $40{ }^{\circ} \mathrm{C}$. This procedure was carried out in triplicate and samples were stored into a desiccator under vacuum at room temperature.

\section{Mean diameter and zeta potential}

Mean diameter and zeta potential were measured in triplicate using a Zetasizer Nano ZS90 (Malvern) at 25 ${ }^{\circ} \mathrm{C}$ at a final concentration of $1 \mathrm{mg} \cdot \mathrm{mL}^{-1}$. Samples were diluted in Milli-Q water and $\mathrm{NaCl} 10 \mathrm{mmol}$ for size and zeta potential analysis, respectively.

\section{Morphological analysis}

A morphological evaluation was conducted by scanning electron microscopy (SEM) in a SSX-550 microscope (Shimadzu). Samples were dried in a vacuum oven (Tecnal), mounted on aluminum stubs, and sputtered with gold (IC-50 Ion Coater, Shimadzu). The micrographs were obtained at accelerating voltage of 10 or $15 \mathrm{kV}$ with different magnifications.

\section{Fourier-transform infrared spectroscopy}

Fourier-transform infrared spectroscopy (FTIR) was carried out with an IR-Prestige-21 spectrophotometer (Shimadzu) using KBr pellets (4 mg of sample and $196 \mathrm{mg}$ of spectroscopic grade $\mathrm{KBr}$ ). Spectra were obtained at 64 scans. $\mathrm{min}^{-1}$, resolution of $4 \mathrm{~cm}^{-1}$ and wavenumber range from $4000 \mathrm{~cm}^{-1}$ to $400 \mathrm{~cm}^{-1}$.

\section{Nuclear magnetic resonance spectroscopy}

Nuclear magnetic resonance (NMR) spectra was obtained in an Avance III NMR 400 (Bruker) operating at 400.13 MHz for ${ }^{1} \mathrm{H}$ and $100.61 \mathrm{MHz}$ for ${ }^{13} \mathrm{C}$. Samples were previously prepared in deuterated water $\left(\mathrm{D}_{2} \mathrm{O}\right)$.

\section{RESULTS AND DISCUSSION}

\section{Preparation of HA-Lys nanoparticles}

Nanoparticles were obtained by interaction between HA and Lys solutions without any further purification. This nanoscale material is the result of a spontaneous formation possibly by ionic interaction between carboxylic acid of HA and primary amine of Lys, as demonstrated in Figure 1. Previous studies have already reported this kind of selfassembled nanoparticles using another polysaccharide, chitosan, for various purposes in the pharmaceutical field (Sonvico et al., 2006).

After dripping, HA-Lys nanoparticles in solution showed a macroscopic homogeneous aspect with opalescent bluish white color resulting from the Brownian motion of colloidal structures. After drying, this product presented a powdery consistency and white color.

\section{Mean diameter and zeta potential}

Table I summarizes results of size and zeta potential as mean \pm standard deviation (SD). The mean size of HA-Lys nanoparticles was $134.1 \mathrm{~nm}$. According to Bos and Meinardi (2000), dermal penetration can occur for chemical compounds lower than $500 \mathrm{Da}$. Nevertheless, it has been shown that diffusion of high-MW corpuscles is drastically impeded in the 
<smiles>NCCCC([NH3+])C(=O)O</smiles><smiles>CC(O)C(O)C(O)C(O)C(=O)[O-]</smiles>
$+$

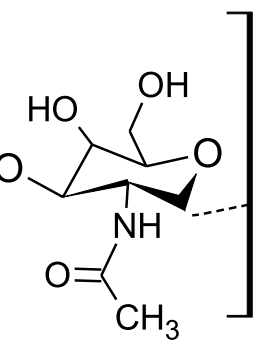<smiles>NCCCC([NH3+])C(=O)O</smiles>

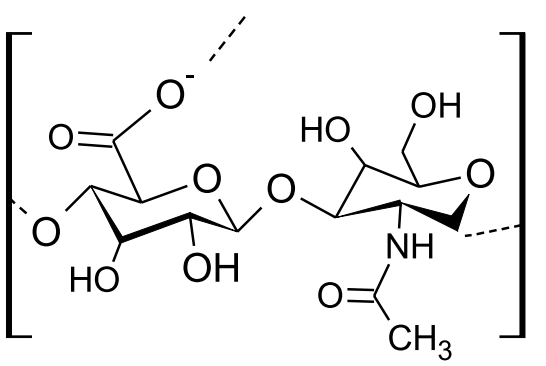

FIGURE 1 - Scheme of ionic interaction between HA and Lys.

stratum corneum. As nanoparticles have molar masses in the order of $10^{6} \mathrm{Da}$ and greater, no significant transport over an intact dermal barrier is to be expected for human beings (Schneider et al., 2009). In that sense, nanoparticles lower than $300 \mathrm{~nm}$ show penetration most likely along two possible routes: the intercellular route, following lipid channels between corneocytes to deeper skin layers and the appendage route though hair follicles and sweat glands (Schneider et al., 2009; Rancan et al., 2012). Therefore, HALys nanoparticles present a suitable mean size for topical application and penetration may occur though lipid channels between corneocytes, hair follicles or sweat glands.

TABLE I - Size and zeta potential of HA-Lys nanoparticles

\begin{tabular}{lcc}
\hline Material & $\begin{array}{c}\text { Size } \\
(\mathrm{nm} \pm \mathrm{SD})\end{array}$ & $\begin{array}{c}\text { Zeta potential } \\
(\mathrm{mV} \pm \mathrm{SD})\end{array}$ \\
\hline HA-Lys nanoparticles & $134.1 \pm 32.0$ & $-59.8 \pm 9.0$ \\
\hline
\end{tabular}

Considering zeta potential, HA-Lys nanoparticles demonstrated a negative value, which is consistent with the anionic nature of HA due to the presence of carboxylic groups. Zeta potential is an important parameter to determine stability of nanoparticles in aqueous systems. In general, higher zeta potential values $(>30 \mathrm{mV})$ provide an electrostatic repulsion among particles that leads to the formation of more stable nanosystems (Frozza et al., 2010). In that sense, HA-Lys nanoparticles revealed suitable stability in colloidal suspension.

\section{Morphological analysis}

Images obtained by SEM of HA and Lys (Figures $2 \mathrm{a}$ and $2 \mathrm{~b}$, respectively) were performed at $2,400 \mathrm{X}$ magnification. Both HA and Lys showed agglomerates of large size. However, HA-Lys complex at 35,000 $\mathrm{X}$ magnification (Figure 2c) were almost spherical in shape and showed nanometric size and smooth surface. These data are consistent with the mean size obtained by Zetasizer Nano ZS90 in the literature (Sonvico et al., 2006; Oyarzun-Ampuero et al., 2011).

\section{Fourier-transform infrared spectroscopy}

Figure 3 depicts FTIR spectra of HA, Lys and HALys nanoparticles. A broad stretching band of hydroxyl (a)

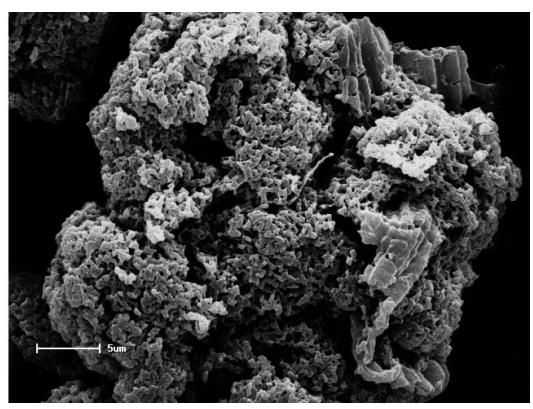

(b)

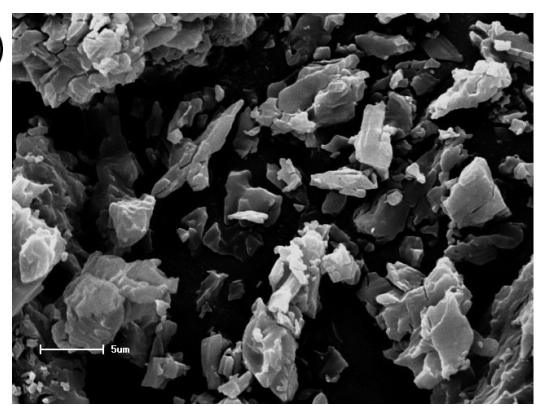

(c)

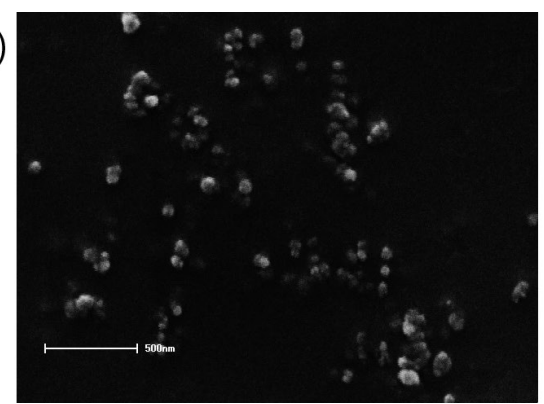

FIGURE 2 - SEM micrographs of HA (a), Lys (b) and HA-Lys nanoparticles (c). 
groups was recorded at $3443 \mathrm{~cm}^{-1}$ in FTIR spectrum of HA (Figure 3a). Two bands at 1720 and $1648 \mathrm{~cm}^{-1}$ corresponded to carbonyl stretching bands of carboxylic acid and amide, respectively. Ether bands were assigned at 1151 and 1034 $\mathrm{cm}^{-1}$ (Silverstein, Webster, 2000; Pavia, Lampman, Kriz, 2010). On the other hand, Lys (Figure 3b) presented a stretching band at $3170 \mathrm{~cm}^{-1}$ corresponding to amine groups. Two bands were assigned at 2981 and $2894 \mathrm{~cm}^{-1}$ due to symmetric and asymmetric $\mathrm{CH}_{2}$ stretching, respectively. A carbonyl stretching band of carboxylic acid was observed at $1690 \mathrm{~cm}^{-1}$. Bands at 1588 and $1148 \mathrm{~cm}^{-1}$ were assigned to $\mathrm{N}-\mathrm{H}$ in-plane bending and $\mathrm{C}-\mathrm{N}$ stretching of amine, respectively (Silverstein, Webster, 2000; Pavia, Lampman, Kriz, 2010).

In general, FTIR spectrum of HA-Lys nanoparticles (Figure 3c) showed similar bands of raw materials. However, the carbonyl stretching band of carboxylic acid of HA was not assigned for HA-Lys nanoparticles. In addition, FTIR spectrum of HA-Lys nanoparticles demonstrated a band at $2625 \mathrm{~cm}^{-1}$ attributed to quaternary ammonium salt. As has been discussed elsewhere (Pavia, Lampman, Kriz, 2010), all ammonium salts display a broad band between 2200 and $3300 \mathrm{~cm}^{-1}$ due to a combination of bands of $\mathrm{NR}^{4+}$ group. In that sense, these data confirm the ionic interaction proposed for self-assembled nanoparticles of HA-Lys involving both carboxyl group of HA and amine group of Lys.

\section{Nuclear magnetic resonance spectroscopy}

Figure 4a represents signals of ${ }^{1} \mathrm{H}$ NMR spectrum

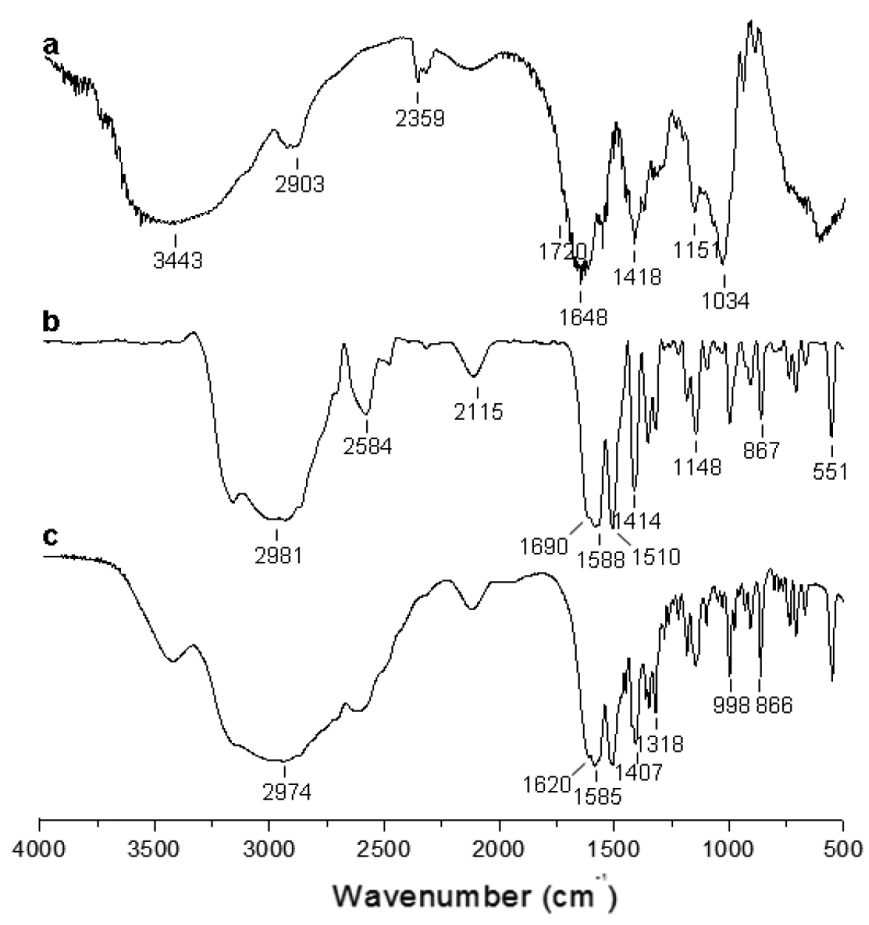

FIGURE 3 - FTIR spectra of HA (a), Lys (b) and HA-Lys nanoparticles (c).

of Lys that corresponded to its characteristic groups. The signal assignment at $\delta 3.64 \mathrm{ppm}(\mathrm{H1})$ of ${ }^{1} \mathrm{H}$ NMR spectrum of Lys was attributed to the chemical shift of $\mathrm{CH}_{2}$ group attached to primary amine. A signal at $\delta 2.90$ ppm was assigned to $\mathbf{C H}$ group attached to carbonyl group (Silverstein, Webster, 2000; Pavia, Lampman, Kriz, 2010). Similar signals were observed in ${ }^{1} \mathrm{H}$ NMR spectrum<smiles>CC(CCCC(C)C(=O)O)C(N)=O</smiles>
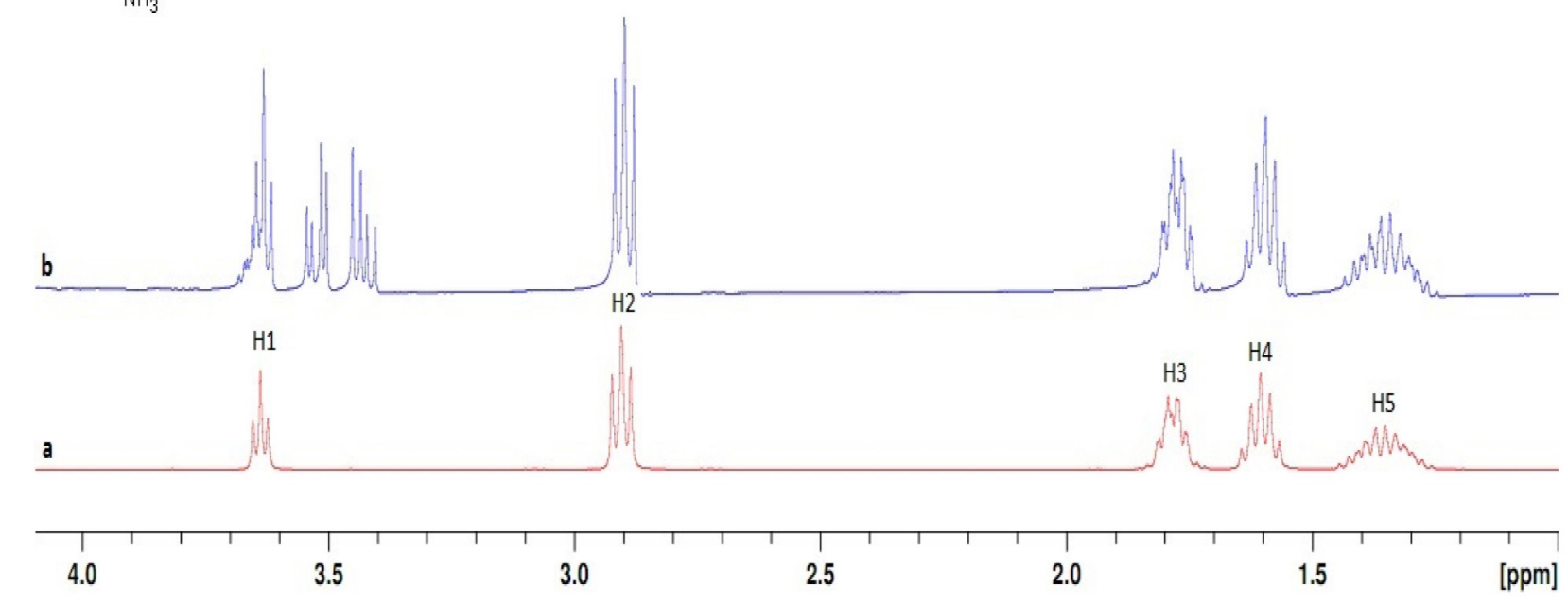

FIGURE 4 - ${ }^{1} \mathrm{H}$ NMR spectra of Lys (a) and HA-Lys nanoparticles (b) at $400.13 \mathrm{MHz}$ in $\mathrm{D}_{2} \mathrm{O}$. 
of HA-Lys nanoparticles (Figure 4b), however typical signals of HA were assigned at $\delta 3.2-3.8 \mathrm{ppm}$ which were attributed to the chemical shift of $\mathbf{C H}$ groups attached to oxygen (Pavia, Lampman, Kriz, 2010). The presence of few signals related to HA can be explained by its lower amount in the final nanomaterial.

Figure 5 shows details of regions between $\delta 3.55$ $3.75 \mathrm{ppm}(\mathbf{H 1})$ and $\delta 2.70-3.10 \mathrm{ppm}(\mathbf{H 2})$ of ${ }^{1} \mathrm{H}$ NMR spectra of Lys and HA-Lys nanoparticles. Chemical shifts can be observed in both regions (H1 and H2) when final HA-Lys nanoparticles were compared to raw material (Lys). In addition, no chemical shift was recorded to other hydrogens related to signals H3, H4, and H5 (data not shown). These chemical shifts in particular regions of ${ }^{1} \mathrm{H}$ NMR spectrum of HA-Lys nanoparticles confirmed that interaction between HA and Lys occurred by participation of amine groups of Lys.

Lysine presented a ${ }^{13} \mathrm{C}$ NMR spectrum (Figure 6a) consistent with the literature (Auxilio et al., 2008) in which typical signals were recorded at $\delta 174.5 \mathrm{ppm}(\mathrm{C1})$ that corresponded to carbonyl carbon and $\delta 54.5$ and $39.2 \mathrm{ppm}$ (C2 and $\mathbf{C 3}$, respectively) that were assigned to carbons near to amine groups.

In ${ }^{13} \mathrm{C}$ NMR spectrum of HA-Lys nanoparticles (Figure 6b), two additional signals were observed that were attributed to carbons attached to oxygen atoms due to the presence of HA in the final nanomaterial.
Figure 7 demonstrates a detail of the region between $\delta 38-55$ ppm of ${ }^{13} \mathrm{C}$ NMR spectra of Lys and HA-Lys nanoparticles. As previously observed in ${ }^{1} \mathrm{H}$ NMR analysis, chemical shifts were also registered to C2 and C3 carbons when ${ }^{13} \mathrm{C}$ NMR spectrum of HALys nanoparticles was compared to ${ }^{13} \mathrm{C}$ NMR spectrum of Lys. No chemical shift was assigned to other carbons (data not shown). These data also confirmed that interaction between HA and Lys occurred by involving amine groups of Lys.

Taking into account FTIR and NMR data, nanoparticles of HA-Lys were successfully prepared by self-assembling involving ionic interaction between carboxyl group of HA and amine group of Lys. This result is consistent with studies that previously reported ionic interrelations of self-organized nanoparticles of lecithin and chitosan (Sonvico et al., 2006) and polyarginine and hyaluronic acid (Oyarzun-Ampuero et al., 2011).

\section{CONCLUSION}

Hyaluronic acid-lysine nanoparticles were successfully prepared by a simple one-step dripping procedure as confirmed by SEM analysis. A nanometersized material with suitable stability in aqueous medium was obtained. FTIR and NMR data confirmed that selfassembled nanoparticles were formed by ionic interaction

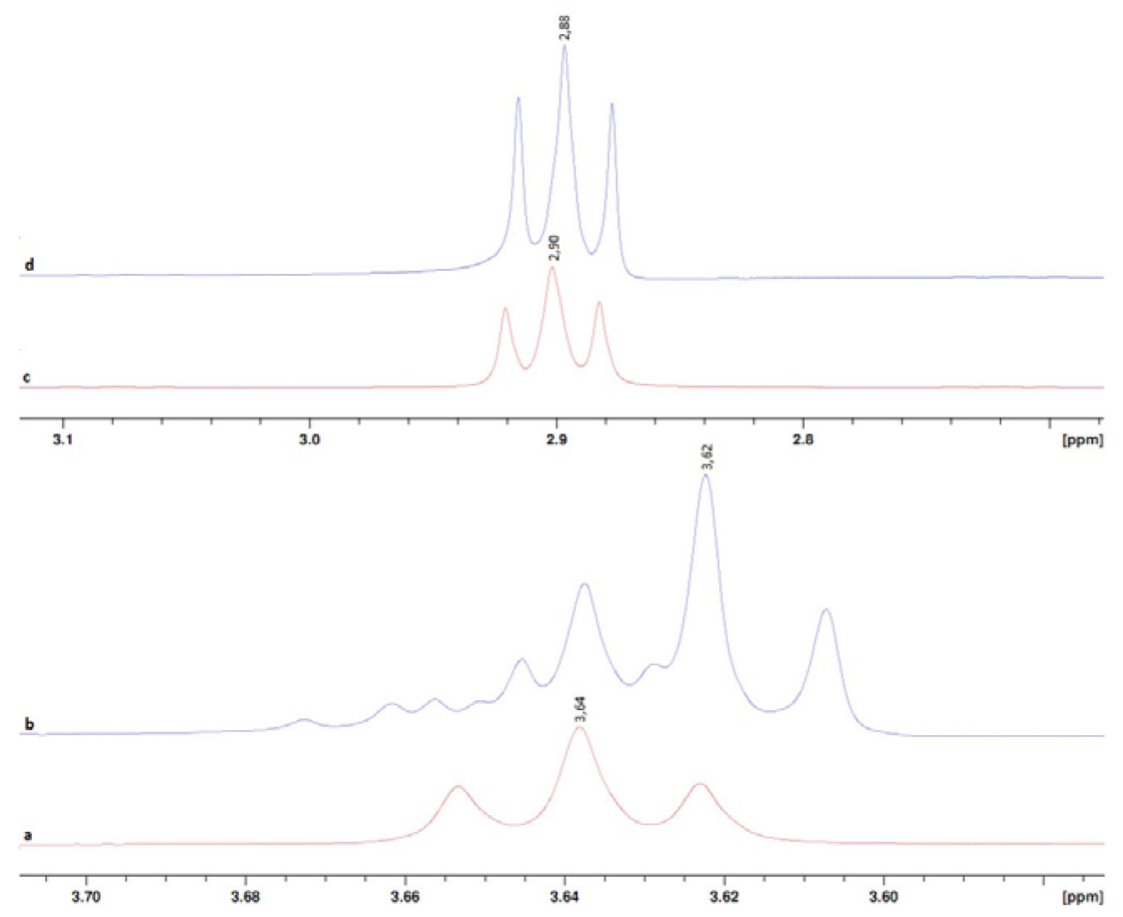

FIGURE 5 - Details of regions between $\delta 3.55-3.75 \mathrm{ppm}(\mathbf{H 1})$ and $\delta 2.70-3.10 \mathrm{ppm}(\mathbf{H 2})$ of ${ }^{1} \mathrm{H}$ NMR spectra of Lys (a) and HALys nanoparticles (b) at $400.13 \mathrm{MHz}$ in $\mathrm{D}_{2} \mathrm{O}$. 
$\prod_{\mathrm{HO}}^{0} \overbrace{\mathrm{NH}_{3}^{+}}^{5} \underbrace{4}_{6} \underbrace{\mathrm{NH}_{2}}_{3}$

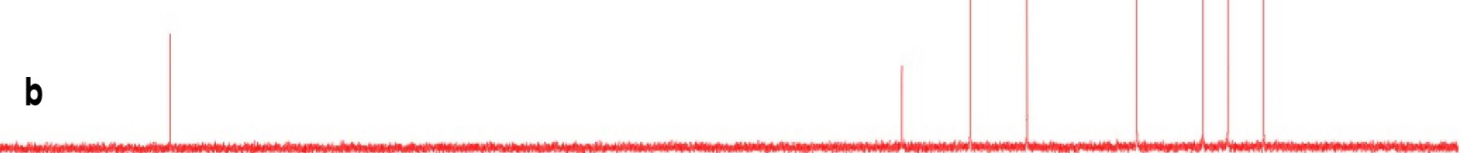

$\mathrm{C} 4 \mathrm{C5}$

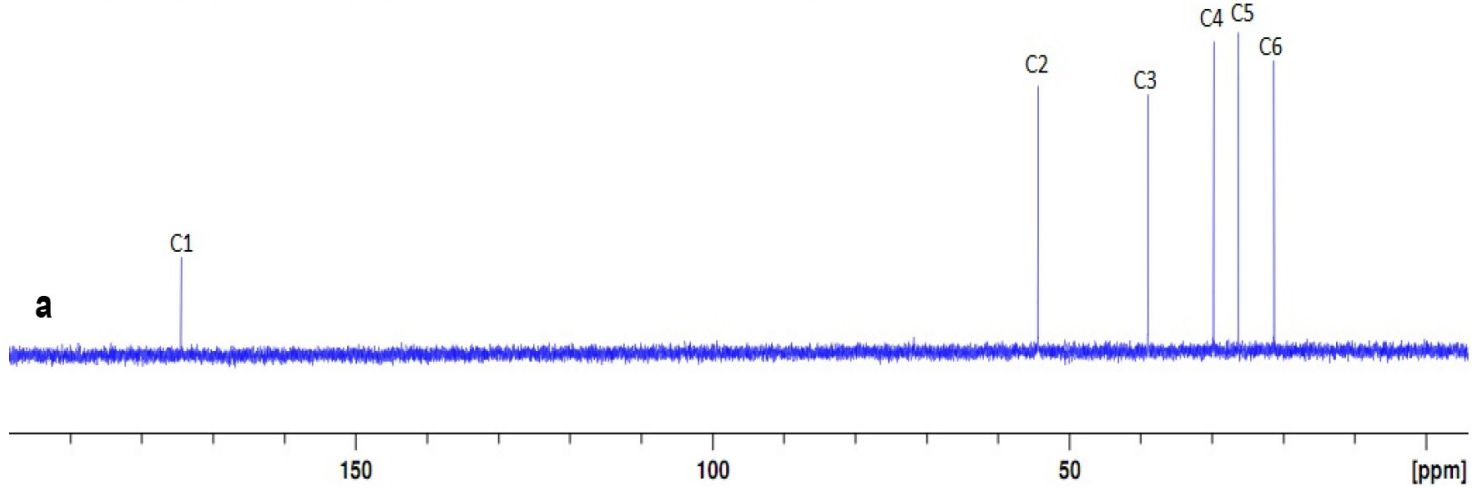

FIGURE $6-{ }^{13} \mathrm{C}$ NMR spectra of Lys (a) and HA-Lys nanoparticles (b) at 100.61 $\mathrm{MHz}$ in $\mathrm{D}_{2} \mathrm{O}$.

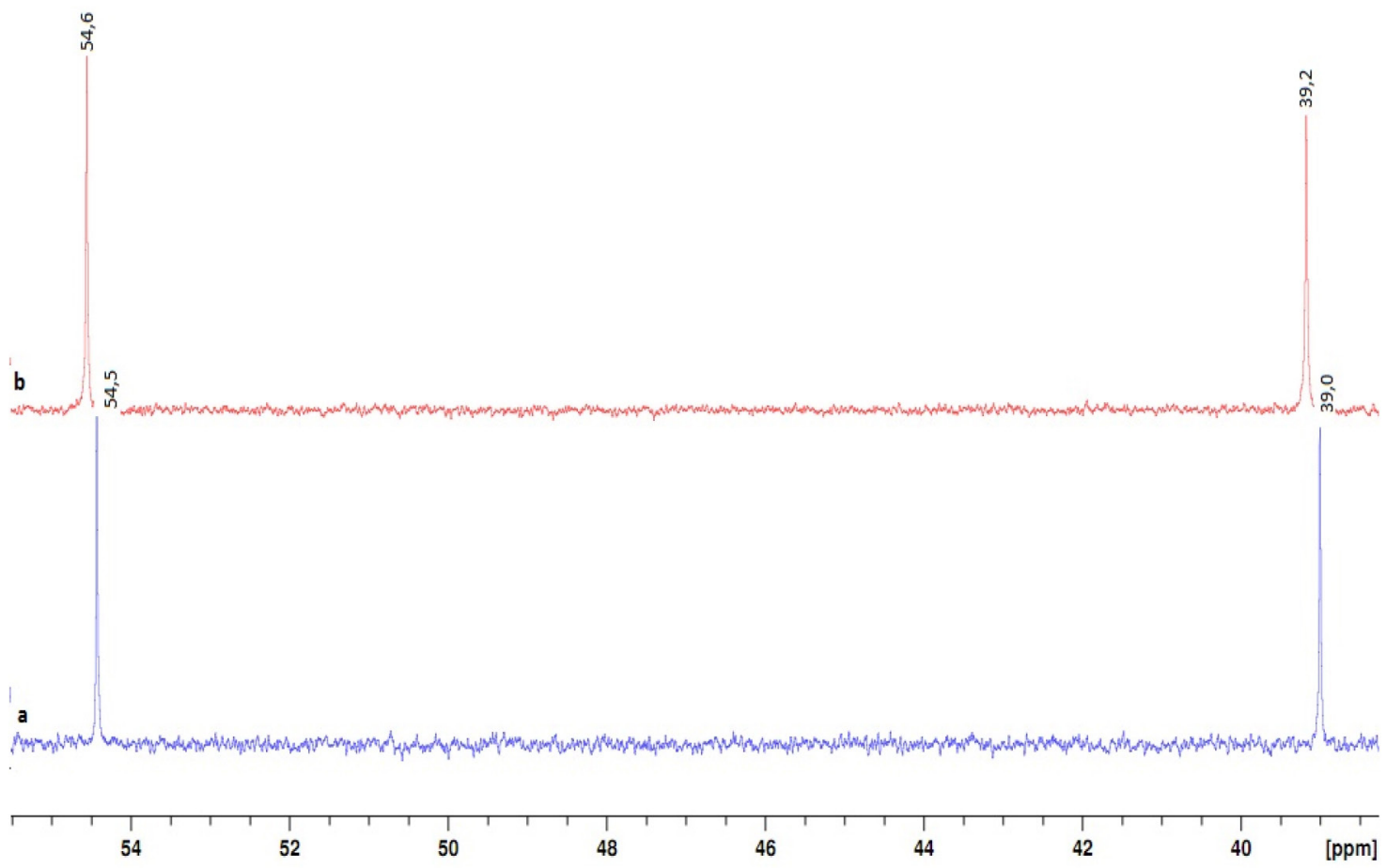

FIGURE 7 - Details of the region between $\delta 38-55$ ppm (C2 and C3) of ${ }^{13} \mathrm{C}$ NMR spectra of Lys (a) and HA-Lys nanoparticles (b) at $100.61 \mathrm{MHz}$ in $\mathrm{D}_{2} \mathrm{O}$.

between carboxyl group of HA and amine group of Lys. In summary, these physicochemical features suggest that HA-Lys nanoparticles can be further used as a topical dermal filling.

\section{ACKNOWLEDGMENTS}

The authors are grateful to CAPES and CNPq (Brazil) for financial support, and the Academic Publishing 
Advisory Center (Centro de Assessoria de Publicação Acadêmica, CAPA - www.capa.ufpr.br) of the Federal University of Paraná for assistance with English language editing.

\section{REFERENCES}

AUXILIO, A. R.; ANDREWS, P. C.; JUNK, P. C.; SPICCIA, L.; NEUMANN, D.; RAVERTY, W.; VANDERHOEK, N.; PRINGLE, J. M. Functionalised pseudo-boehmite nanoparticles as an excellent adsorbent material for anionic dyes. J. Mater. Chem., v.18, p.2466-2474, 2008.

BEER, K. Dermal fillers and combinations of fillers for facial rejuvenation. Clin. Dermatol., v.27, p.427-432, 2009.

BORN, T. Hyaluronic Acids. Clin. Plast. Surg., v.33, p.525$538,2006$.

BOS, J.D.; MEINARDI, M.M.H.M. The 500 Dalton rule for the skin penetration of chemical compounds and drugs. Exp. Dermatol., v.9, p.165-169, 2000.

BRANDT, F.S.; CAZZANIGA, A. Hyaluronic acid fillers: restylane and perlane. Facial Plast. Surg. Clin. North Am., v.15, p.63-76, 2007.

EDWARDS, P.C.; FANTASIA, J.E.; IOVINO, R. Foreign body reaction to Hyaluronic Acid (Restylane): an adverse outcome of lip augmentation. J. Oral Maxillofac. Surg., v.64, p.1296-1299, 2006.

FROZZA, R.L.; BERNARDI, A.; PAESE, K.; HOPPE, J.B.; DA SILVA, T.; BATTASTINI, A.M., POHLMANN, A.R.; GUTERRES, S.S.; SALBEGO, C.; Characterization of trans-resveratrol-loaded lipid-core nanocapsules and tissue distribution studies in rats. J. Biomed. Nanotechnol., v.6, p.694-703, 2010.

GUTERRES, S. S.; ALVEZ, M. P.; POHLMANN, A. R. Polymeric nanoparticles, nanospheres and nanocapsules, for cutaneous applications. Drug Target Insights, v.2, p.147-157, 2007.

NELSON, D. L.; COX, M. M. Princípios de bioquímica de Lehninger. 5. ed. Porto Alegre: Artmed, 2011. p.1273.
OYARZUN-AMPUERO, F.A.; GOYCOOLEA, F.M.; TORRES, D.; ALONSO, M.J. A new drug nanocarrier consisting of polyarginine and hyaluronic acid. Eur. $J$. Pharm. Biopharm., v.79, p.54-57, 2011.

PAVIA, D. L.; LAMPMAN, G. M.; KRIZ, G. S. Introdução à espectroscopia. 4. ed. São Paulo: Cengage Learning, 2010. $700 \mathrm{p}$.

RANCAN, F.; GAO, Q.; GRAF, C.; TROPPENS, S.; HADAM, S.; HACKBARTH, S.; KEMBUAN, C.; BLUMEPEYTAVI, U.; RÜHL, E.; LADEMANN, J.; VOGT, A. Skin penetration and cellular uptake of amorphous silica nanoparticles with variable size, surface functionalization, and colloidal stability. ACS Nano, v.6, p.6829-6842, 2012.

REQUENA, L.; REQUENA, C.; CHRISTENSEN, L; ZIMMERMANN, U. S.; KUTZNER, H.; CERRONI, L. Adverse reactions to injectable soft tissue fillers. $J$. Am. Acad. Dermatol., v.64, p.1-34, 2011.

ROBERT, L.; LABAT-ROBERT, J.; ROBERT, A.-M. Physiology of skin aging. Clin. Plast. Surg., v.39, p.1-8, 2012.

SÁNCHEZ-CARPINTERO, I.; CANDELAS, D.; RUIZRODRÍGUES, R. Dermal fillers: types, indications, and complications. Actas Dermosifiliogr., v.101, n.5, p.381-393, 2010.

SILVERSTEIN, R. M.; WEBSTER, F. X. Identificação espectrométrica de compostos orgânicos. 6.ed. Rio de Janeiro: Livros Técnicos e Científicos Editora, 2000. p.460.

SONVICO, S.; CAGNANI, A.; ROSSI, A.; MOTTA, S.; DI BARI, M. T.; CAVATORTA, F.; ALONSO, M. J.; DERIU, A.; COLOMBO, P. Formation of self-organized nanoparticles by lecithin/chitosan ionic interaction. Int. J. Pharm., v.324, p.67-73, 2006.

SCHNEIDER, M.; STRACKE, F.; HANSEN, S.; SCHAEFER, U.F. Nanoparticles and their interactions with the dermal barrier. Dermatoendocrinology, v.1, p.197-206, 2009.

Received for publication on $13^{\text {th }}$ March 2015 Accepted for publication on $15^{\text {th }}$ September 2016 
